\title{
Prognostic role of extracellular matrix metalloproteinase inducer/CD147 in gastrointestinal cancer: a meta-analysis of related studies
}

\author{
Xiaohui Huang ${ }^{1, *}$, Weisong Shen ${ }^{2, *}$, Hongqing $\mathbf{X i}^{1}$, Kecheng Zhang ${ }^{1}$, Jianxin Cui ${ }^{1}$, \\ Bo Wei ${ }^{1}$, Lin Chen ${ }^{1}$ \\ ${ }^{1}$ Department of General Surgery, Chinese People's Liberation Army General Hospital, Beijing 100853, China \\ ${ }^{2}$ Department of General Surgery, Jinling Hospital, Medical School of Nanjing University, Nanjing 210002, China \\ *These authors have contributed equally to this work \\ Correspondence to: Lin Chen, email: chenlinbj@163.com \\ Bo Wei, email: pu_384632271@sina.com \\ Keywords: gastrointestinal cancer, CD 147, prognosis, meta-analysis \\ Received: June 16, $2016 \quad$ Accepted: October 03, $2016 \quad$ Published: October 19, 2016
}

\section{ABSTRACT}

The prognostic role of Extracellular matrix metalloproteinase inducer (EMMPRIN/ CD147) in gastrointestinal cancer remains controversial. We systematically reviewed the evidence of assessment of CD147 expression in gastrointestinal cancer to help clarify this issue. Pubmed, Embase, Cochrane Library and Web of Science databases were searched to identify eligible studies to evaluate the association of CD147 expression and disease-free and overall survival of gastrointestinal cancer. Hazard ratios (HRs) were pooled to estimate the effect. CD147 overexpression was significantly correlated with poor disease-free survival (HR 2.38, 95\% CI 1.43-3.97) and overall survival (HR 1.64, 95\% CI 1.25-2.14) of cancer patients. Furthermore, CD147 overexpression was significantly association with TNM stage (TIII/TIV vs TI/TII: OR 3.60, 95\% CI 1.85-7.01), the depth of invasion (T3/T4 vs T1/T2: OR $2.04,95 \%$ CI 1.25-3.33), lymph node metastasis (positive vs negative: $2.35,95 \%$ CI 1.14-4.86), distant metastasis (positive vs negative: OR 4.78, 95\% CI 1.43-16.00). Our analyses demonstrate that CD147 was effectively predictive of worse prognosis in gastrointestinal cancer. Moreover, Identifying CD147 may help identify new drug targets for cancer therapy.

\section{INTRODUCTION}

Gastrointestinal cancers are the main malignant tumors in both men and women worldwide [1, 2]. Although progression has been made in its diagnosis and treatment, some gastrointestinal cancers are still incurable. This is largely because most patients are at an advanced stage at the time of diagnosis, so have a correspondingly poor prognosis. Disease prognosis correlates directly with the incidence of carcinoma relapse, which is mainly caused by early metastasis. Therefore, the prediction of tumor relapse and the prevention of early metastasis is a promising therapy for gastrointestinal cancer. It is therefore very important to confirm prognostic markers for gastrointestinal cancer which can help identify better preventive methods for gastrointestinal cancer patients.
Several molecular markers, such as matrix metalloproteinase (MMPs), vascular endothelial growth factor (VEGF), E-cadherin, and epidermal growth factor, have been proven to associate with prognosis for carcinoma patients [3-6]. Among the biomarkers, the expression of extracellular matrix metalloproteinase inducer (CD147) has attracted interest. CD147 is one of cell glycoprotein of immunoglobulin super family. It is highly expressed in malignant carcinomas and is a prognosis marker of cancer progression [7]. CD147 arouses normal cells to express MMPs, which are a group of zinc-dependent proteins that degrade the expression of extracellular matrix (ECM) $[8,9]$. Low expression of the ECM surrounding primary tumors is essential for carcinoma invasion and metastasis [8]. 
As well as the important function of CD147 in tumor progression, its role in carcinoma invasiveness was also identified in several malignancies. Some reports demonstrated that CD147 expression was correlated with the prognosis of various human carcinomas [10-15]. CD147 has also been reported to be associated with tumor progression, metastasis, relapse, and prognosis of gastrointestinal carcinoma [16-22]. However, not all findings are consistent. Meta-analysis is a powerful method that overcomes the deficiency of small sample sizes of a individual centre [23]. Thus, we perform the meta-analysis to evaluate the prognostic significance of CD147 in gastrointestinal cancer.

\section{RESULTS}

\section{Study selection and characteristics}

A total of 213 researches were retrieved by the search strategies described. After browsing the abstract and full-text, seven studies were into meta-analysis. All studies met the inclusion criteria and quality assessment standard. The selection process is shown in Figure 1, and the main characteristics of the seven studies are summarized in Table 1. Three studies were of gastric cancer, and four were of colorectal cancer. Three studies evaluated patients from China one from Korea, one from Norway, one from Germany, and one from Japan. The seven studies consisted of a total of 1,993 patients, with sample sizes varying from 210 to 436 patients.

\section{The association between CD147 and survival in gastrointestinal cancer}

CD147 in gastrointestinal cancer tissues was shown to be significantly associated with poor overall survival of cancer patients (combined HR 1.64, 95\% CI 1.25-2.14). Subgroup analysis by malignant disease also revealed a significant relationship between CD147 and overall survival in gastric cancer (HR 1.43, 95\% CI 1.11-1.85) and colorectal cancer (HR 1.93, 95\% CI 1.17-3.20) (Figure 2).

We also assessed the association between CD147 and disease-free survival in gastrointestinal cancer. As shown in Figure 3, CD147 expression in gastrointestinal cancer tissues was associated with poor disease-free survival of gastrointestinal cancer (combined HR 2.38, 95\% CI 1.43-3.97). Moreover, subgroup analysis showed a significant relationship between CA147 and diseasefree survival in both gastric carcinoma (HR 1.63, 95\% CI 1.13-2.36) and colorectal carcinoma (HR 3.18, 95\% CI 2.02-5.02).

\section{The association between CD147 and clinical features}

We next assessed the association between CD147 and clinical characteristic s of gastrointestinal carcinoma. As shown in the forest plots, CD147 was significantly associated with TNM stage (TIII/TIV vs TI/TII: combined OR 3.60, 95\% CI 1.85-7.01) (Figure 4), depth of invasion

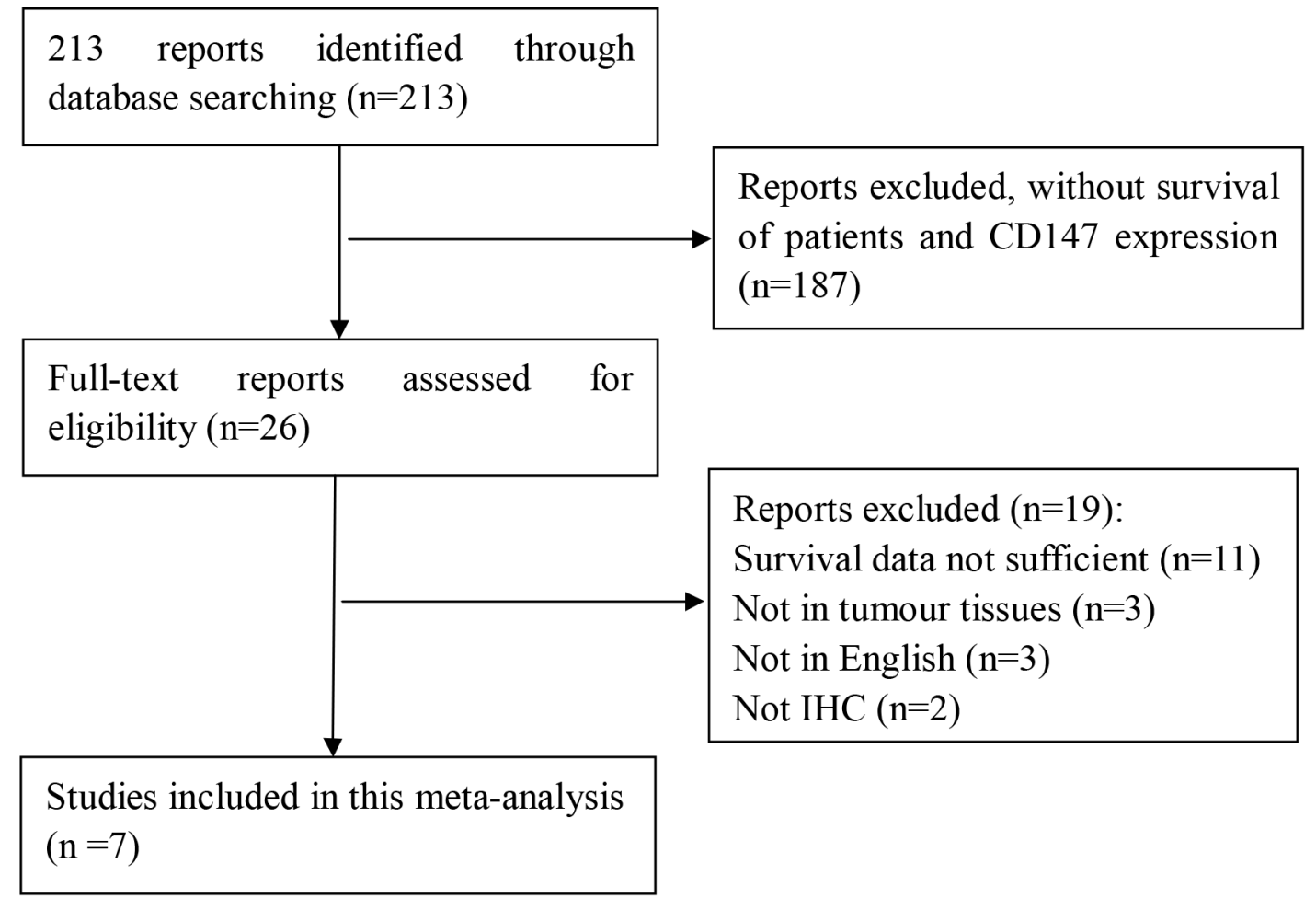

Figure 1: Flow chart of studies included. 
Table 1: Major features of the included studies

\begin{tabular}{|c|c|c|c|c|c|c|c|c|c|c|c|}
\hline Study & Year & $\begin{array}{l}\text { Study } \\
\text { location }\end{array}$ & $\begin{array}{c}\text { Number } \\
\text { of } \\
\text { patients }\end{array}$ & Races & $\begin{array}{l}\text { Malignant } \\
\text { disease }\end{array}$ & Technology & $\begin{array}{l}\text { Detected } \\
\text { sample }\end{array}$ & Antibody & $\begin{array}{l}\text { Staining } \\
\text { patterns }\end{array}$ & $\begin{array}{c}\text { Cut- } \\
\text { off }\end{array}$ & $\begin{array}{c}\text { CD147 } \\
\text { expression(\%) }\end{array}$ \\
\hline Zheng [16] & 2006 & Japan & 234 & Asian & $\begin{array}{l}\text { Gastric } \\
\text { cancer }\end{array}$ & $\begin{array}{l}\text { TMA and } \\
\text { IHC }\end{array}$ & Tissue & $\begin{array}{l}\text { Mouse anti- } \\
\text { EMMPRIN }\end{array}$ & $\begin{array}{l}\text { Membrane } \\
\text { and } \\
\text { cytoplasm }\end{array}$ & $\mathrm{P}>5 \%$ & $64.96 \%$ \\
\hline Zhang [17] & 2012 & China & 436 & Asian & $\begin{array}{l}\text { Gastric } \\
\text { cancer }\end{array}$ & $\begin{array}{l}\text { TMA and } \\
\text { IHC }\end{array}$ & Tissue & $\begin{array}{l}\text { Mouse } \\
\text { monoclonal } \\
\text { antibody }\end{array}$ & Membrane & $\mathrm{S} \geq 4$ & $66.51 \%$ \\
\hline Chu [18] & 2014 & China & 223 & Asian & $\begin{array}{l}\text { Gastric } \\
\text { cancer }\end{array}$ & IHC & Tissue & $\begin{array}{l}\text { Mouse } \\
\text { anti-human } \\
\text { CD147 } \\
\text { monoclonal } \\
\text { antibody }\end{array}$ & $\begin{array}{l}\text { Membrane } \\
\text { and } \\
\text { cytoplasm }\end{array}$ & $\mathrm{S} \geq 1$ & $59.64 \%$ \\
\hline Boye [19] & 2012 & Norway & 277 & Caucasian & $\begin{array}{l}\text { Colorectal } \\
\text { cancer }\end{array}$ & $\mathrm{IHC}$ & Tissue & $\begin{array}{l}\text { Goat } \\
\text { polyclonal } \\
\text { anti- } \\
\text { EMMPRIN } \\
\text { antibody }\end{array}$ & $\begin{array}{l}\text { Membrane } \\
\text { and } \\
\text { cytoplasm }\end{array}$ & $\mathrm{P} \geq 5 \%$ & $71.48 \%$ \\
\hline Zhu [20] & 2013 & China & 328 & Asian & $\begin{array}{l}\text { Colorectal } \\
\text { cancer }\end{array}$ & $\begin{array}{l}\text { TMA and } \\
\text { IHC }\end{array}$ & Tissue & $\begin{array}{l}\text { Mouse } \\
\text { anti-human } \\
\text { HAb18G/ } \\
\text { CD147 } \\
\text { monoclonal } \\
\text { antibody }\end{array}$ & $\begin{array}{l}\text { Membrane } \\
\text { and } \\
\text { cytoplasm }\end{array}$ & $\mathrm{S} \geq 1$ & $63.11 \%$ \\
\hline $\begin{array}{l}\text { Stenzinger } \\
{[21]}\end{array}$ & 2011 & Germany & 285 & Caucasian & $\begin{array}{l}\text { Colorectal } \\
\text { cancer }\end{array}$ & $\begin{array}{l}\text { TMA and } \\
\text { IHC }\end{array}$ & Tissue & $\begin{array}{l}\text { Rabbit } \\
\text { polyclonal } \\
\text { antibody }\end{array}$ & $\begin{array}{l}\text { Membrane } \\
\text { and } \\
\text { cytoplasm }\end{array}$ & $\mathrm{S}>1$ & $49.82 \%$ \\
\hline Jung [22] & 2011 & Korea & 210 & Asian & $\begin{array}{l}\text { Colorectal } \\
\text { cancer }\end{array}$ & $\begin{array}{l}\text { TMA and } \\
\text { IHC }\end{array}$ & Tissue & $\begin{array}{l}\text { Monoclonal } \\
\text { antibody }\end{array}$ & $\begin{array}{l}\text { Membrane } \\
\text { and } \\
\text { cytoplasm }\end{array}$ & $\mathrm{S} \geq 3$ & $62 \%$ \\
\hline
\end{tabular}

TMA, tissue microarray; IHC, immunohistochemistry; P, proportion of stained tumor cells; S, scores for intensity and proportion of stained tumor cells.

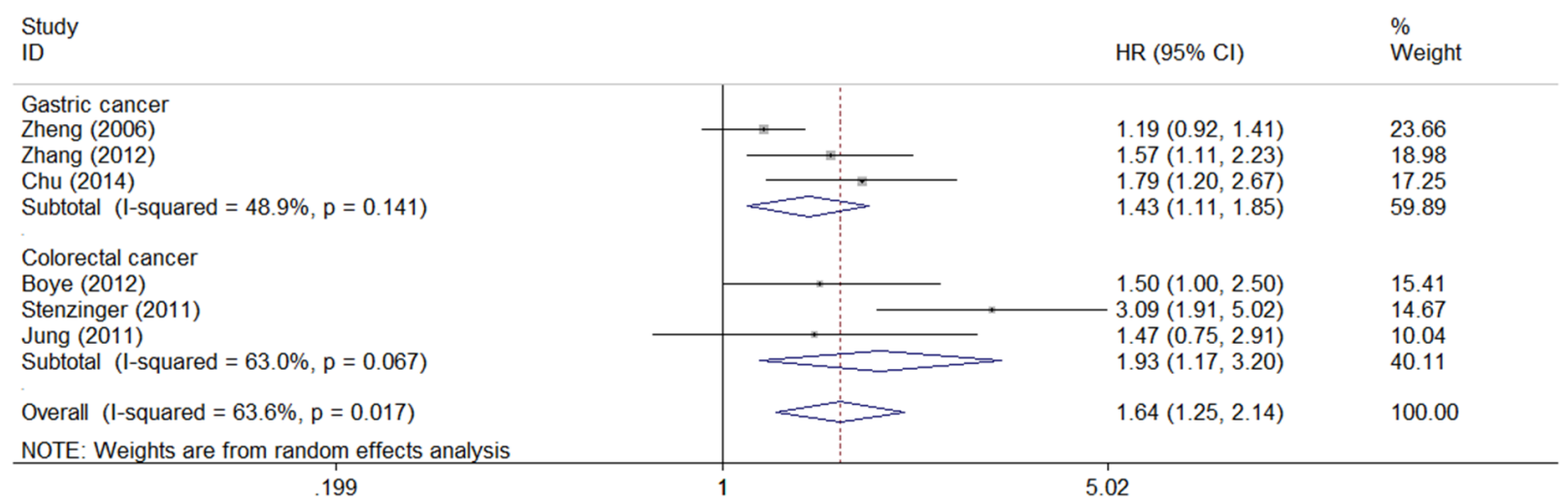

Figure 2: Meta-analysis of impact of CD147 expression on overall survival of patients. Results are presented as individual and pooled $\mathrm{HR}$, and $95 \% \mathrm{CI}$. 
(T3/T4 vs T1/T2: combined OR 2.04, 95\% CI 1.25-3.33) (Figure 5), lymph node metastasis (positive vs negative: combined OR 2.35, 95\% CI 1.14-4.86) (Figure 6), and distant metastasis (positive vs negative: combined OR 4.78, 95\% CI 1.43-16.00) (Figure 7).

\section{Publication bias}

Publication bias was assessed based on overall survival using Begg's test. No publication bias was identified in these studies $(p=0.573)$. Similarly, the funnel plots for publication bias revealed a degree of symmetry (Figure 8).

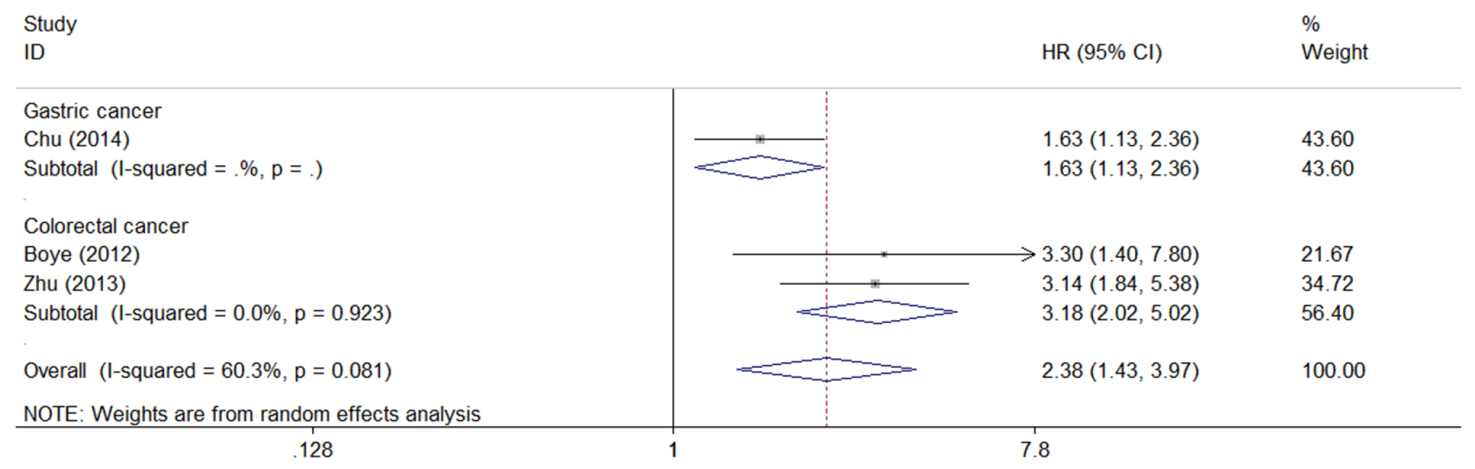

Figure 3: Meta-analysis of impact of CD147 expression on disease-free survival of patients. Results are presented as individual and pooled $\mathrm{HR}$, and 95\% CI.

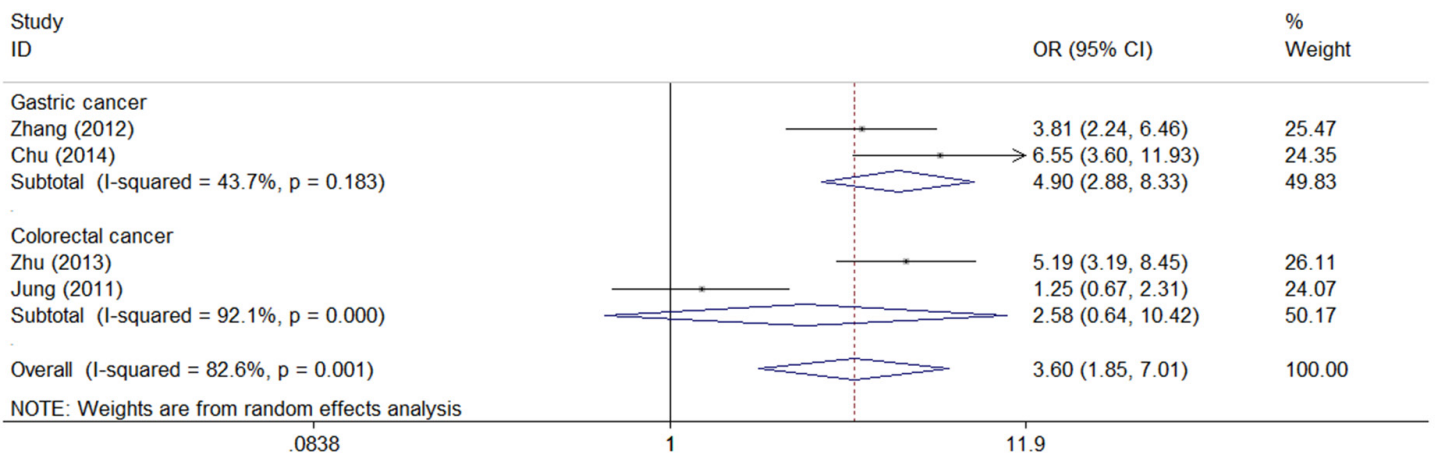

Figure 4: Meta-analysis of impact of CD147 expression on TNM stage of patients. Results are presented as individual and pooled OR, and $95 \% \mathrm{CI}$.

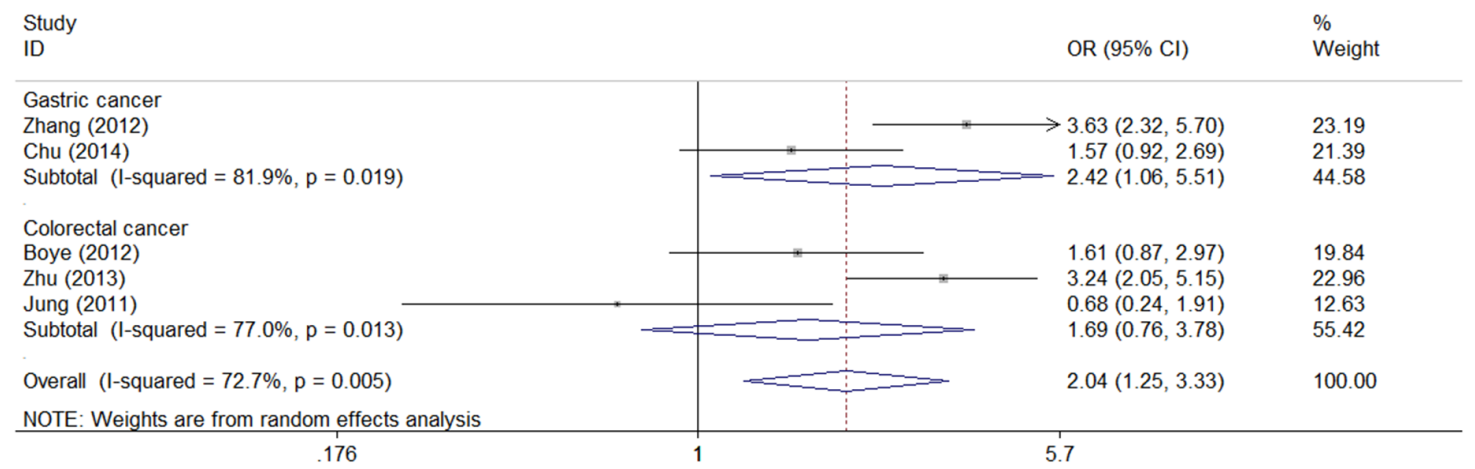

Figure 5: Meta-analysis of impact of CD147 expression on the depth of invasion of patients. Results are presented as individual and pooled OR, and 95\% CI. 


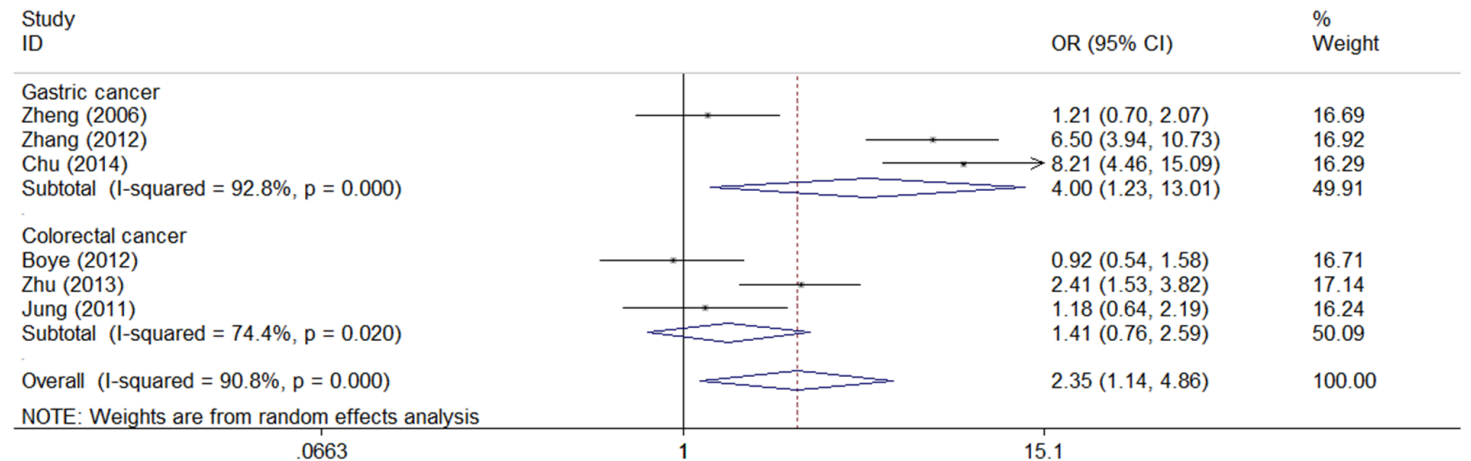

Figure 6: Meta-analysis of impact of CD147 expression on lymph node metastasis of patients. Results are presented as individual and pooled $\mathrm{OR}$, and 95\% CI.

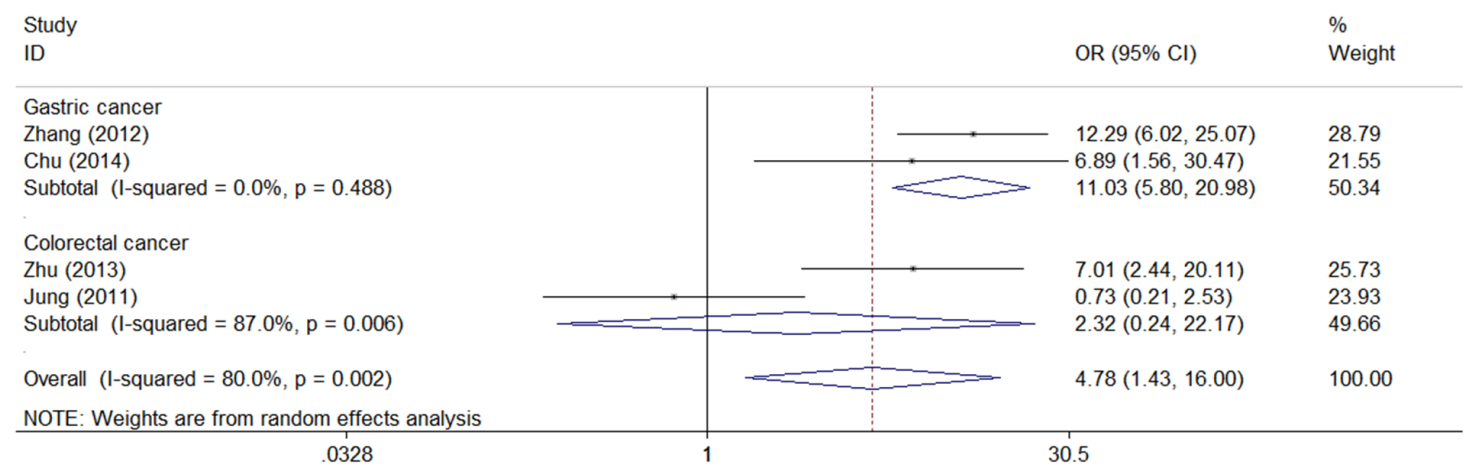

Figure 7: Meta-analysis of impact of CD147 expression on distant metastasis of patients. Results are presented as individual and pooled $\mathrm{OR}$, and $95 \% \mathrm{CI}$.

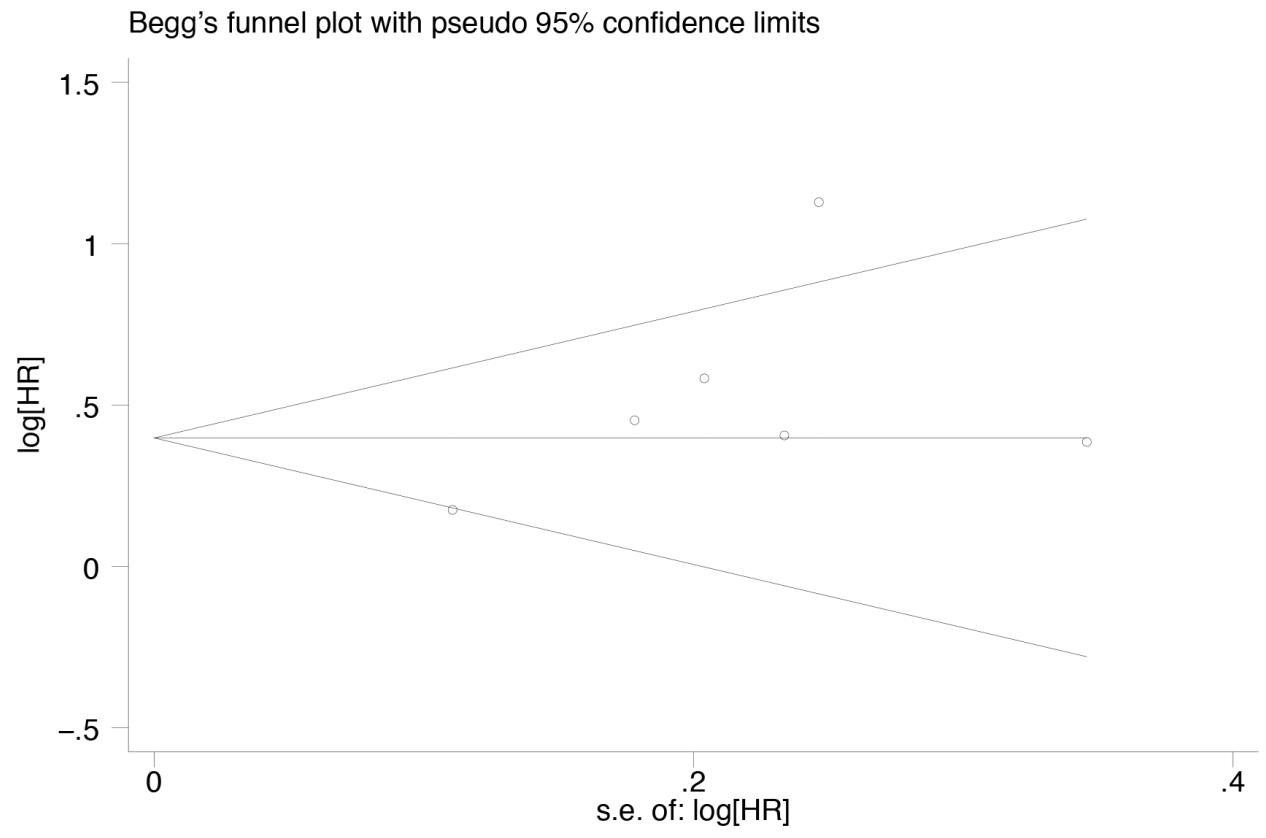

Figure 8: Funnel plot for the evaluation of potential publication bias in the impact of CD147 expression on overall survival. 


\section{DISCUSSION}

CD147 is abundantly expressed in various types of cancer tissue, and may promote cancer metastasis by regulating the processes of cellular substrate and adhesion [24-26]. CD147 also plays a key role in degradation of the ECM through MMP induction [27-29], regulates VEGF expression [30], stimulates proliferation, migration, and cell survival independently of MMPs [31], and leads to multidrug resistance to some chemotherapeutic drugs [32].

To our knowledge, this is the first meta-analysis to assess the association between CD147 expression and disease-free and overall survival of gastrointestinal cancer patients. Our meta-analysis combined the results of 1,993 gastrointestinal cancer patients from seven studies. The meta-analysis indicated that CD147 expression can be used to significantly predict poor disease-free and overall survival of gastrointestinal cancer patients. Subgroup analysis showed that the high expression of CD147 can predict poor prognosis in both gastric cancer and colorectal cancer.

The tissue invasion, lymphatic metastases and distant metastases of carcinomas, are the major prognostic factors of solid cancers [21]. Traditional clinical characteristics, such as size and stage of gastrointestinal cancer, can predict clinical survival of patients. In our study, significant correlations were observed between CD147 and clinical characteristics including the depth of invasion, lymph node metastasis, TNM stage, and distant metastasis.

Our meta-analysis has a number of advantages. First, it rigorously adhered to reporting recommendations for tumor marker prognostic studies (REMARK) guidelines, and carefully searched relevant studies from PubMed, Embase, Cochrane Library, and Web of Science databases. Second, the enrolled researches all had a satisfactory quality based on the strict inclusion criteria. Third, subgroup analysis effectively minimized heterogeneity of the included studies and further explored the application of CD147 as a predictive marker for gastric and colorectal cancer. Fourth, Begg's funnel plots indicated that no publication bias existed in the meta-analysis. This reflected our methodological assessment of the researches to avoid selection biases. Our comprehensive literature search method also minimized publication bias.

Nevertheless, our meta-analysis has some limitations. First, it included just seven studies, resulting in a relative insufficiency in the subgroup analysis, particularly when there was only one study to represent results. Second, the method of calculating HRs from reports might have led to heterogeneity. The HR of one enrolled study was calculated by the method previously documented by Tierney et al [22]. This reported the number of death events of patients and the log-rank data or p-value, which enable the HR to be approximated. Although the calculated HR might be not as reliable as one retrieved from reported studies, we did not find any major deviation of results when comparing our calculated HR with the statistical significance of the study itself. Third, only a small number of included patients were enrolled in our meta-analysis compared with other meta-analyses. Therefore, further study about CD147 is essential to indentify the prognostic role of CD147.

Because of the significant heterogeneity of the enrolled studies, we adopted random effects models when pooling data. Subgroup analysis revealed that the heterogeneity may be due to the difference in malignant disease. The features of cancers might differ based on diverse tumor locations. We conducted subgroup analysis according to malignant disease, and the pooled analysis of gastric cancer and colorectal cancer indicated that the high expression of CD147was associated with poor survival.

Identifying a role for CD147 in driving tumor invasion and metastasis not only helps us understand this biomarker of cancer progression, but also develop new drug target. Our meta-analysis indicates that CD147 expression predicts a bad survival in gastrointestinal carcinomas.CD147 can therefore be used as a prognostic marker for gastrointestinal cancer, and as a predictor of cancer relapse.

\section{MATERIALS AND METHODS}

\section{Literature search and search strategy}

We conducted this meta-analysis following the PRISMA statement [33]. A literature search was performed in Pubmed, Embase, Cochrane Library and Web of Science databases for clinical research published before June 2016 that that assessed CD147 as a prognostic factor for survival of patients with gastrointestinal cancer using immunohistochemistry. The search used the following terms: "gastrointestinal cancer", "CD147" OR "EMMPRIN" and "prognosis" OR "prognostic" OR "survival". The references of all relevant articles were evaluated to find other related studies. Article language was limited to English. Two reviewers independently assessed the eligibility of the studies. Agreement was reached for the discrepancies by discussion.

\section{Inclusion and exclusion criteria}

Inclusion criteria: (1) Study evaluated the correlation between CD147 expression and survival of gastrointestinal cancer patients; (2) Study assessed CD147 expression in tumor tissues using immunohistochemistry; (3) If the same team published more than one article, only the most recent or detailed study were included; (4) Study provided sufficient information allowing for estimation of hazard ratios (HRs) and their 95\% confidence intervals (CIs); (5) Study was published as a full text in the English language. Exclusion criteria: Impossible to extract effective data from the study's defined clinical outcomes. 


\section{Quality assessment of included studies}

Quality assessment and methodological assessment was peer-reviewed by 2 reviewers (Xiaohui Huang and Weisong Shen) independently in each of the acceptable studies, who scored them by the ELCWP scale and REMARK guidelines [34]. This validated quality assessment system is based on four major classifications: scientific design, description of immunohistochemistry methods, generalizability of results, and the analysis of the study data. Each category had a maximal score of 10 points with an overall maximum theoretical score of 40 points. The final scores were presented as percentages. Studies with $\geq 60 \%$ points were considered high quality and were included in the meta-analysis. The two investigators reported the quality of included studies independently, and reach a consensus value for each item.

\section{Data extraction}

Two reviewers (Xiaohui Huang and Weisong Shen) independently extracted relevant data. The following data were extracted from each study: first author, year of publication, study period, number of participants, tumor characteristics, survival. HRs and 95\% CIs were used to calculate the survival. If HRs and $95 \%$ CIs were not directly reported in the included studies, we evaluated the values in the original studies by using the methods illustrated by Tierney et al [35]. If disagreements arose, agreements were reached for the discrepancies by discussion with another author (Bo Wei).

\section{Statistical analysis}

Stata 12.0 software (StatCorp, College Station, TX, USA) was used for statistical analysis. Forest plots were used to estimate the effect of expression on disease-free and overall survival. HR values $>1$ were judged to indicate a association between CD147 expression and poor outcome. TNM stage (TIII/TIV vs TI/TII), the depth of invasion (T3/T4 vs T1/T2), lymph node metastasis (positive vs negative), and distant metastasis (positive vs negative) were compared using odds ratios (ORs). A p value of $<0.05$ was regarded as significant. Heterogeneity was assessed by use of Cochran Q and I2 statistics and considered significant at $\mathrm{p}<0.1$. If heterogeneity existed, the analysis used the random effects model. Publication bias was assessed by use of Begg's funnel plot.

\section{CONFLICTS OF INTEREST}

The authors declare no conflicts of interest.

\section{FUNDING}

This work was supported by the Special Scientific Research Foundation of Health Sector from the National Health and Family Planning Commission of China (No. 201302016) and project supported by the National High Technology Research and Development Program of China (No. 2012AA02A504).

\section{REFERENCES}

1. Ferlay J, Shin HR, Bray F, Forman D, Mathers C, Parkin DM. Estimates of worldwide burden of cancer in 2008: GLOBOCAN 2008. International journal of cancer Journal international du cancer. 2010; 127:2893-2917.

2. Center MM, Jemal A, Smith RA, Ward E. Worldwide variations in colorectal cancer. CA: a cancer journal for clinicians. 2009; 59:366-378.

3. Shen W, Xi H, Wei B, Chen L. The prognostic role of matrix metalloproteinase 2 in gastric cancer: a systematic review with meta-analysis. Journal of cancer research and clinical oncology. 2014; 140:1003-1009.

4. Xing X, Tang YB, Yuan G, Wang Y, Wang J, Yang Y, Chen $\mathrm{M}$. The prognostic value of E-cadherin in gastric cancer: a meta-analysis. International journal of cancer Journal international du cancer. 2013; 132:2589-2596.

5. Yasui W, Hata J, Yokozaki H, Nakatani H, Ochiai A, Ito $\mathrm{H}$, Tahara E. Interaction between epidermal growth factor and its receptor in progression of human gastric carcinoma. International journal of cancer Journal international du cancer. 1988; 41:211-217.

6. Fondevila C, Metges JP, Fuster J, Grau JJ, Palacin A, Castells A, Volant A, Pera M. p53 and VEGF expression are independent predictors of tumour recurrence and survival following curative resection of gastric cancer. British journal of cancer. 2004; 90:206-215.

7. Nabeshima K, Iwasaki H, Koga K, Hojo H, Suzumiya J, Kikuchi M. Emmprin (basigin/CD147): matrix metalloproteinase modulator and multifunctional cell recognition molecule that plays a critical role in cancer progression. Pathology international. 2006; 56:359-367.

8. Curran S, Murray GI. Matrix metalloproteinases: molecular aspects of their roles in tumour invasion and metastasis. European journal of cancer (Oxford, England: 1990). 2000; 36:1621-1630.

9. Gabison EE, Hoang-Xuan T, Mauviel A, Menashi S. EMMPRIN/CD147, an MMP modulator in cancer, development and tissue repair. Biochimie. 2005; 87:361-368.

10. Zhong X, Li M, Nie B, Wu F, Zhang L, Wang E, Han Y. Overexpressions of RACK1 and CD147 associated with poor prognosis in stage $\mathrm{T} 1$ pulmonary adenocarcinoma. Annals of surgical oncology. 2013; 20:1044-1052. 
11. Bi XC, Liu JM, He HC, Ye YK, Han ZD, Dai QS, Liang YX, Cai C, Chen JH, Chen XB, Qin GQ, Zeng GH, Zhong WD. Extracellular matrix metalloproteinase inducer: a novel poor prognostic marker for human seminomas. Clinical \& translational oncology: official publication of the Federation of Spanish Oncology Societies and of the National Cancer Institute of Mexico. 2012; 14:190-196.

12. Piao S, Zhao S, Guo F, Xue J, Yao G, Wei Z, Huang Q, Sun Y, Zhang B. Increased expression of CD147 and MMP-9 is correlated with poor prognosis of salivary duct carcinoma. Journal of cancer research and clinical oncology. 2012; 138:627-635.

13. Pertega-Gomes N, Vizcaino JR, Miranda-Goncalves V, Pinheiro C, Silva J, Pereira H, Monteiro P, Henrique RM, Reis RM, Lopes C, Baltazar F. Monocarboxylate transporter 4 (MCT4) and CD147 overexpression is associated with poor prognosis in prostate cancer. BMC cancer. 2011; 11:312.

14. Afonso J, Longatto-Filho A, Baltazar F, Sousa N, Costa FE, Morais A, Amaro T, Lopes C, Santos LL. CD147 overexpression allows an accurate discrimination of bladder cancer patients' prognosis. European journal of surgical oncology: the journal of the European Society of Surgical Oncology and the British Association of Surgical Oncology. 2011; 37:811-817.

15. Liu F, Cui L, Zhang Y, Chen L, Wang Y, Fan Y, Lei T, Gu F, Lang R, Pringle GA, Zhang X, Chen Z, Fu L. Expression of HAb18G is associated with tumor progression and prognosis of breast carcinoma. Breast cancer research and treatment. 2010; 124:677-688.

16. Zheng HC, Takahashi H, Murai Y, Cui ZG, Nomoto K, Miwa S, Tsuneyama K, Takano Y. Upregulated EMMPRIN/ CD147 might contribute to growth and angiogenesis of gastric carcinoma: a good marker for local invasion and prognosis. British journal of cancer. 2006; 95:1371-1378.

17. Shou ZX, Jin X, Zhao ZS. Upregulated expression of ADAM17 is a prognostic marker for patients with gastric cancer. Annals of surgery. 2012; 256:1014-1022.

18. Chu D, Zhu S, Li J, Ji G, Wang W, Wu G, Zheng J. CD147 expression in human gastric cancer is associated with tumor recurrence and prognosis. PloS one. 2014; 9:e101027.

19. Boye K, Nesland JM, Sandstad B, Haugland Haugen M, Maelandsmo GM, Flatmark K. EMMPRIN is associated with S100A4 and predicts patient outcome in colorectal cancer. British journal of cancer. 2012; 107:667-674.

20. Zhu S, Chu D, Zhang Y, Wang X, Gong L, Han X, Yao L, Lan M, Li Y, Zhang W. EMMPRIN/CD147 expression is associated with disease-free survival of patients with colorectal cancer. Medical oncology (Northwood, London, England). 2013; 30:369.

21. Stenzinger A, Wittschieber D, von Winterfeld M, Goeppert B, Kamphues C, Weichert W, Dietel M, Rabien A, Klauschen F. High extracellular matrix metalloproteinase inducer/CD147 expression is strongly and independently associated with poor prognosis in colorectal cancer. Human pathology. 2012; 43:1471-1481.

22. Jung EJ, Lee JH, Min BW, Kim YS, Choi JS. Clinicopathologic significance of fascin, extracellular matrix metalloproteinase inducer, and ezrin expressions in colorectal adenocarcinoma. Indian journal of pathology \& microbiology. 2011; 54:32-36.

23. Nordmann AJ, Kasenda B, Briel M. Meta-analyses: what they can and cannot do. Swiss medical weekly. 2012; 142:w13518.

24. Tang Y, Kesavan P, Nakada MT, Yan L. Tumor-stroma interaction: positive feedback regulation of extracellular matrix metalloproteinase inducer (EMMPRIN) expression and matrix metalloproteinase-dependent generation of soluble EMMPRIN. Molecular cancer research: MCR. 2004; 2:73-80.

25. Vigneswaran N, Beckers S, Waigel S, Mensah J, Wu J, Mo J, Fleisher KE, Bouquot J, Sacks PG, Zacharias W. Increased EMMPRIN (CD 147) expression during oral carcinogenesis. Experimental and molecular pathology. 2006; 80:147-159.

26. Nakamura K, Kodama J, Hongo A, Hiramatsu Y. Role of emmprin in endometrial cancer. BMC cancer. 2012; 12:191.

27. Sidhu SS, Mengistab AT, Tauscher AN, LaVail J, Basbaum C. The microvesicle as a vehicle for EMMPRIN in tumorstromal interactions. Oncogene. 2004; 23:956-963.

28. Biswas C, Zhang Y, DeCastro R, Guo H, Nakamura T, Kataoka H, Nabeshima K. The human tumor cell-derived collagenase stimulatory factor (renamed EMMPRIN) is a member of the immunoglobulin superfamily. Cancer research. 1995; 55:434-439.

29. Guo H, Majmudar G, Jensen TC, Biswas C, Toole BP, Gordon MK. Characterization of the gene for human EMMPRIN, a tumor cell surface inducer of matrix metalloproteinases. Gene. 1998; 220:99-108.

30. Tang Y, Nakada MT, Kesavan P, McCabe F, Millar H, Rafferty P, Bugelski P, Yan L. Extracellular matrix metalloproteinase inducer stimulates tumor angiogenesis by elevating vascular endothelial cell growth factor and matrix metalloproteinases. Cancer research. 2005; 65:3193-3199.

31. Sidhu SS, Nawroth R, Retz M, Lemjabbar-Alaoui H, Dasari V, Basbaum C. EMMPRIN regulates the canonical Wnt/beta-catenin signaling pathway, a potential role in accelerating lung tumorigenesis. Oncogene. 2010; 29:4145-4156.

32. Marieb EA, Zoltan-Jones A, Li R, Misra S, Ghatak S, Cao J, Zucker S, Toole BP. Emmprin promotes anchorageindependent growth in human mammary carcinoma cells by stimulating hyaluronan production. Cancer research. 2004; 64:1229-1232.

33. Moher D, Liberati A, Tetzlaff J, Altman DG. Preferred reporting items for systematic reviews and meta-analyses: the PRISMA statement. PLoS medicine. 2009; 6:e1000097. 
34. Steels E, Paesmans M, Berghmans T, Branle F, Lemaitre F, Mascaux C, Meert AP, Vallot F, Lafitte JJ, Sculier JP. Role of $\mathrm{p} 53$ as a prognostic factor for survival in lung cancer: a systematic review of the literature with a meta-analysis. The European respiratory journal. 2001; 18:705-719.
35. Tierney JF, Stewart LA, Ghersi D, Burdett S, Sydes MR. Practical methods for incorporating summary time-to-event data into meta-analysis. Trials. 2007; 8:16. 